REMIPE

\title{
IMPLEMENTAÇÃO DE MANUTENÇÃO PREVENTIVA ESTRATÉGICA PARA OS NEGÓCIOS
}

\author{
IMPLEMENTATION OF STRATEGIC PREVENTIVE MAINTENANCE FOR \\ BUSINESS
}

Recebido: 12/1/2018 - Aprovado: 14/03/2018 - Publicado: 26/06/2018 Processo de Avaliação: Double Blind Review

\author{
Albert Vilela de Oliveira ${ }^{1}$ \\ Graduando em Tecnologia em Manutenção Industrial \\ Faculdade de Tecnologia de Osasco - Fatec Osasco \\ albert_vilela@hotmail.com \\ Bruno Borges dos Santos \\ Graduando em Tecnologia em Manutenção Industrial \\ Faculdade de Tecnologia de Osasco - Fatec Osasco \\ borgesdossantosbruno@gmail.com \\ Josvaldo da Silva Santos \\ Graduando em Tecnologia em Manutenção Industrial \\ Faculdade de Tecnologia de Osasco - Fatec Osasco \\ santosjosvaldo@gmail.com \\ Márcio Henrique Magalhães \\ Especialista em Qualidade e Produtividade \\ Faculdade de Tecnologia de Osasco - Fatec Osasco \\ marciohmagalhaes@ig.com.br

\section{Carlos Alberto de Freitas} \\ Especialista em Administração Industrial \\ Faculdade de Tecnologia de Osasco - Fatec Osasco \\ carlos.afreitas@fatec.sp.gov.br
}

\footnotetext{
${ }^{1}$ Autor para correspondência: FATEC Pref. HirantSanazar - FATEC Osasco - R. Pedro Rissato, 30 - Vila dos Remedios, Osasco - SP, 06296-220, Brasil,
}

REMIPE- Revista de Micro e Pequenas Empresas e Empreendedorismo da Fatec Osasco 


\author{
Antonio Carlos S. de Arruda \\ Mestre em Engenharia Elétrica pela USP \\ Faculdade de Tecnologia de Osasco - Fatec Osasco \\ antonio.arruda@fatec.sp.gov.br
}

RESUMO: O presente artigo trata da aplicação de métodos investigativos estruturados para a solução de falhas na produção industrial de uma empresa com a finalidade de tornar a manutenção mais estratégica e eficiente.Os tempos de paradas do maquinário, bem como suas particularidades, contextualizados na estrutura própria da produção e da manutenção da fábrica, foram objetos de uma análise crítica. Tal análise, por meio do planejamento detalhado de uma manutenção preventiva, busca solucionar um problema de inefíciência outrora desconhecido, melhorando assim o desempenho geral da produção da planta em que o estudo é aplicado.O contexto em que se encontra a indústria de papel brasileira, atualmente, também, é objeto de breve análise neste estudo, com o objetivo de proporcionar uma visão de como o mercado global se comporta em relação às tendências de produção do setor.

Obs: Este resumo não atende as exigências do "gênero resumo/científico", o qual deve explicitar em seu conteúdo, os elementos estruturais como: objetivo da pesquisa, aportes teórico-metodológicos, procedimentos metodológicos incluindo: tipo de pesquisa, tipo de abordagem, explicitação do objeto de análise (coleta e seleção de dados) e apresentação dos resultados...

Palavras-chave: preventiva, coladeira, manutenção, paradas.

ABSTRACT: This article deals with the application of structured research methods for solution of failures at company industrial production with the purpose of making the maintenance more strategic and efficient. The downtime of the machinery, as well as its peculiarities, contextualized in the proper production and maintenance structure, will be objects of a analysis that intends, through the detailed planning of a preventive maintenance, to solve a inefficiency problem previously unknown, thereby improving the overall production performance of the plant in which the study is applied. The context in which the Brazilian paper industry is today also briefly analyzed in this study with the aim of providing a notion of how the global market behaves in relation to the sector's production trends.

REMIPE- Revista de Micro e Pequenas Empresas e Empreendedorismo da Fatec Osasco 
Keywords: preventive, necklace machine, maintenance, breakdowns.

\section{INTRODUÇÃO:}

Foi realizado um estudo em uma empresa do ramo de embalagens de papel, onde uma máquina coladeira de caixas de papelão, Modeti 752, apresentou ineficiência produtiva relevante devido a diversos fatores, que podem ser relacionados com a parametrização e manutenção de subconjuntos mecânicos e elétricos do equipamento, e que foram examinados com base no uso de ferramentas de investigação comumente aplicadas no âmbito industrial onde a eficiência dos processos é avaliada em detrimento de falhas diversas.

Após uma análise dos registros de produção de todas as máquinas da empresa, foi constatada uma perda considerável na coladeira por recorrentes paradas do maquinário para manutenções corretivas quando comparada aos demais equipamentos contidos no pátio da fábrica.

O que mais chamou atenção nesta análise de dados é que mesmo tendo uma sistemática de manutenção muito bem implementada, alguns aspectos voltados ao resultado operacional/financeiro da empresa não foram levados em consideração e esta falha é muito comum entre as organizações que não estão acostumados a enxergar o lado estratégico deste tão importante processo.

Para a realização de um estudo das falhas que causaram a ineficiência produtiva, o uso de ferramentas como Diagrama de Ishikawa e Gráficos de Pareto foram empregados sob o enfoque das manutenções não planejadas gerando resultados compreensíveis para a tomada de ações preventivas justificáveis.

\section{REFERECIAL TEÓRICO}

\subsection{MANUTENÇÃO}

O trabalho da manutenção exige um olhar apurado para identificar os possíveis problemas e, dessa maneira, encontrar soluções seguras e viáveis do ponto de vista econômico.

Para MAURÍCIO (2010:8):A manutenção existe para que não haja manutenção, este é o conceito moderno da manutenção em que a satisfação do cliente vem em primeiro lugar, não se paga mais por serviços, mas sim pela solução do problema. No setor de manutenção o cliente pode ser o setor ao qual ele dá apoio (setor produtivo).

REMIPE- Revista de Micro e Pequenas Empresas e Empreendedorismo da Fatec Osasco 
Para VIANA (2002): os principais tipos de manutenção são: corretiva, centrada em confiabilidade, preditiva, produtiva total e preventiva, essa última pode ser classificada, em linhas gerais, como uma manutenção que visa evitar a falha do equipamento ainda que este esteja em condições mínimas de funcionamento.

\subsection{DIAGRAMA DE ISHIKAWA:}

É um processo que permite a analisar e identificar as principais causas de variação do processo ou da ocorrência de um problema.

Segundo RAMOS (2000: 98):

O diagrama de causa e efeito é uma figura composta de linhas e símbolos, que representam uma relação significativa entre um efeito e suas possíveis causas. Este diagrama descreve situações complexas, que seriam muito difíceis de serem descritas e interpretadas somente por palavras. "Existem, provavelmente, várias categorias de causas principais. Frequentemente, estas recaem sobre umas das seguintes categorias: Mão-de-obra, Máquinas, Métodos, Materiais, Meio Ambiente e Meio de Medição conhecidas como os 6Ms.

\subsection{PROCESSOFABRIL DA COLADEIRA:}

Nesse processo as caixas passam por alguns estágios da máquina onde o principal é a passagem de cola em alguns pontos específicos e o deslocamento das caixas por um longo caminho com fitas que vão dobrando a caixa à medida que a fita as força a acompanhar uma geometria específica como mostra a figura 1.

Figura 1 : Processamento da caixa de papelão:

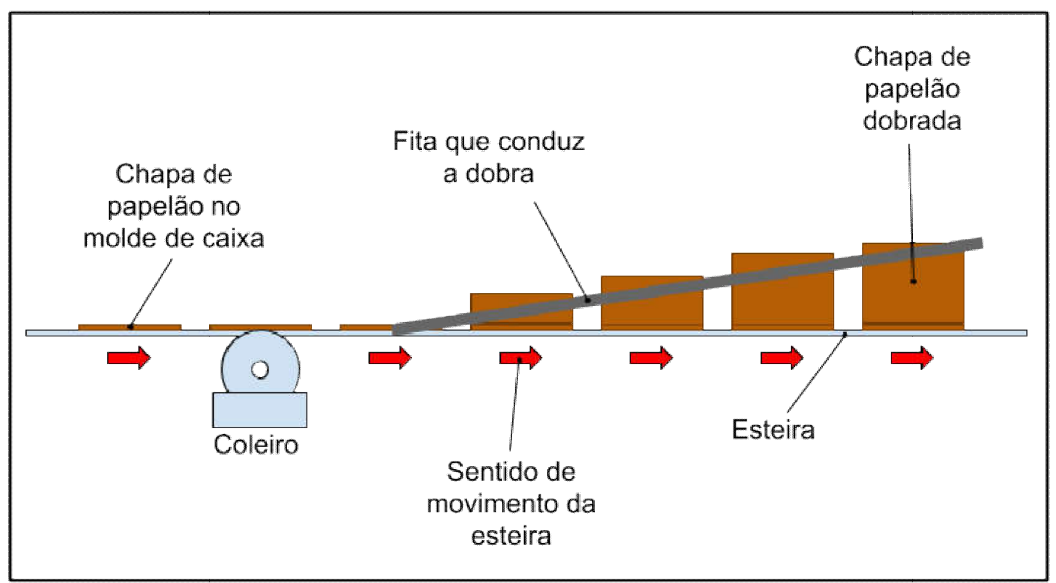

Fonte: elaborada pelos autores.

REMIPE- Revista de Micro e Pequenas Empresas e Empreendedorismo da Fatec Osasco V. 4, N¹, jan.-jun. 2018. 
Essa técnica pode ser combinada em diversas posições para que a chapa de papelão seja dobrada da maneira desejada e de forma contínua. A presença de um coleiro é importante para que a caixa se mantenha com uma resistência mínima com a dobra feita.

\subsection{INDÚSTRIA DO PAPEL NO BRASIL:}

Segundo a Associação Brasileira de Celulose e Papel, nas últimas décadas o brasil tem produzido papel tradicionalmente para seu mercado interno, o consumo per capita brasileiro de papel ainda tem se mostrado bastante inferior ao consumo de países europeus, Canadá, Estados Unidos, Coreia e Japão. Dessa forma, há espaço para crescimento nos próximos anos.

O Brasil exporta principalmente papéis de imprimir e escrever e "kraftliner" para caixas de papelão, importando papel jornal, LWC (Light WeightCoated ou Peso Leve Revestido) usado para catálogos e revistas, CWF (CoatedWoodFree ou isento de pasta mecânica) usado na indústria alimentícia e outros tipos de papéis especiais.

O total das vendas externas de janeiro a dezembro de 2015 foi de 2.021 milhões de dólares. O gráfico 2 mostra a participação de cada região nas exportações no mundo onde mais da metade corresponde à américa latina.

Gráfico 1 -Participação nas exportações de papel pelo mundo:

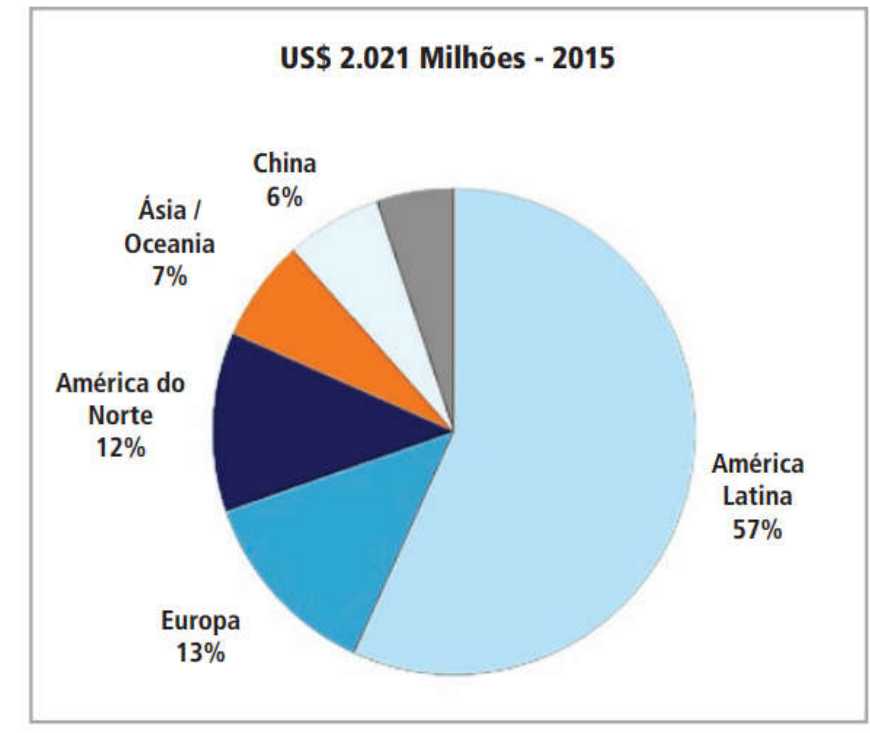

Fonte:Bracelpa.

\section{METODOLOGIA:}

REMIPE- Revista de Micro e Pequenas Empresas e Empreendedorismo da Fatec Osasco V. 4, N¹, jan.-jun. 2018. 
A pesquisa foi realizada em uma fábrica de embalagens que trabalha em turnos de 15 horas por dia está com dificuldades na produção devido a um problema em um de seus setores. Podemos ver na figura 2 como são organizados os setores em relação ao fluxo produtivo por onde as caixas são confeccionadas.

Figura 2 : Fluxo de produção nos setores da fábrica:

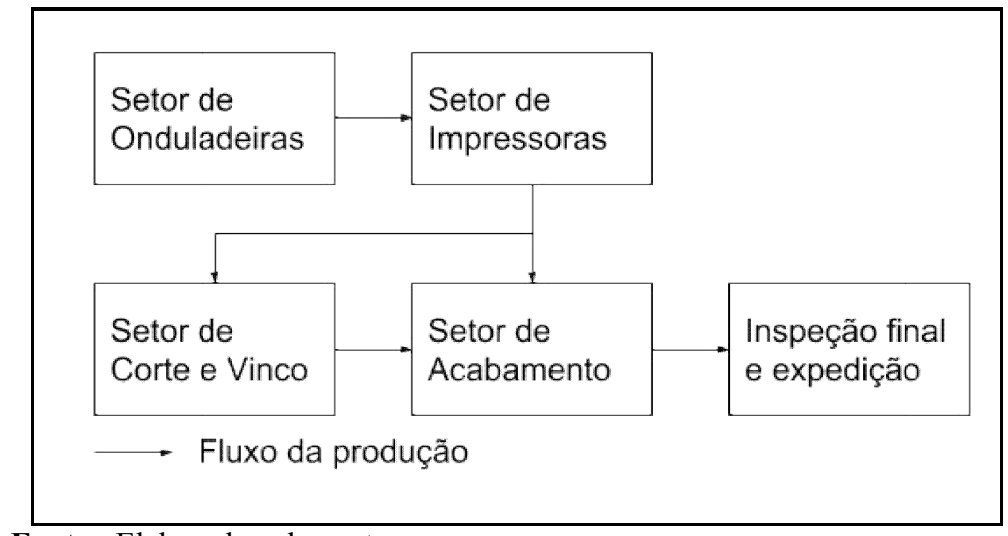

Fonte : Elaborada pelos autores.

Pode-se definir a tarefa de cada setor da empresa pesquisada da seguinte maneira:

- Setor de onduladeiras: as chapas de papelão são confeccionadas dispostas na sobreposição de camadas com uma interface de ondulada para atribuir maior resistência mecânica;

- Setor de impressoras: realiza a tarefa de imprimir nas chapas de caixas informações que o cliente desejar como o logo da empresa e dados logísticos (fragilidade, empilhamento e outros);

- Setor de corte e vinco: prepara as caixas que exigem uma geometria específica para serem dobradas e coladas realizando algumas aparas e vincos na chapa;

- Setor de acabamento: dobra e cola as caixas no formato final para serem enviadas ao cliente;

- Inspeção final e expedição: é onde a qualidade das caixas são revisadas uma última vez para serem enviadas ao cliente.

Para organizar a prioridade de funcionamento de cada máquina na fábrica, segundo os dados da empresa, é utilizada uma classificação $\mathrm{ABC}$, que determina o procedimento de manutenção a que as máquinas são submetidas.

REMIPE- Revista de Micro e Pequenas Empresas e Empreendedorismo da Fatec Osasco 
- Classe A :Manutentor permanente acompanha o processo; Preventiva; Corretiva.

- Classe B : Preventiva; Corretiva.

- Classe C : Corretiva.

A função de colar e dobrar as caixas na fábrica é precedida pela passagem das chapas de papelão no setor de corte e vinco podendo passar antes ainda pela impressora que prepara as chapas para serem dobradas e coladas no processo final.

No intuito de melhorar o desempenho da linha de produção da empresa, uma manutenção preventiva é estudada no intuito de melhorar o desempenho das máquinas no pátio fabril reduzindo o tempo que a máquina fica indisponível cada vez que é parada.

Para a obtenção de dados de $\mathrm{MTBF}^{2}$ e $\mathrm{MTTR}^{3}$, foram coletados os registros do banco de dados Trimbox da empresa e registros de paradas realizados pelos diversos setores de produção durante o primeiro semestre de 2017.

Tabela 1: MTBF e MTTR do primeiro semestre de 2017:

\begin{tabular}{l|c|c|c}
\hline \multicolumn{1}{c|}{ Máquina } & $\begin{array}{c}\text { Classificação } \\
\text { ABC }\end{array}$ & $\begin{array}{c}\text { MTBF } \\
\text { (horas) }\end{array}$ & $\begin{array}{c}\text { MTTR } \\
\text { (minutos) }\end{array}$ \\
\hline Coladeira Modeti & $\mathrm{B}$ & 21.4 & 202 \\
\hline Tomazoni I & $\mathrm{B}$ & 48.1 & 48 \\
\hline Titan & $\mathrm{B}$ & 38.5 & 76 \\
\hline Simon & $\mathrm{B}$ & 38.5 & 31 \\
\hline Vole & $\mathrm{B}$ & 35.0 & 36 \\
\hline Tomazoni II & $\mathrm{B}$ & 12.4 & 36 \\
\hline Eterna I & $\mathrm{C}$ & 128.3 & 50 \\
\hline Onduladeira & $\mathrm{A}$ & 2.0 & 12 \\
\hline Boca de Sapo IV & $\mathrm{C}$ & 128.3 & 73 \\
\hline Eterna II & $\mathrm{C}$ & 35.0 & 35 \\
\hline Boca de Sapo I & $\mathrm{C}$ & 77.0 & 54 \\
\hline Boca de Sapo II & $\mathrm{C}$ & 385.0 & 20 \\
\hline Boca de Sapo III & $\mathrm{C}$ & 385.0 & 10 \\
\hline
\end{tabular}

Fonte: Sistema de registros da empresa pesquisada.

\footnotetext{
${ }^{2}$ MTBF é a abreviatura de mean time betweenfailures e é usado no contexto de manutenção para designar o tempo de médio de funcionamento entre cada parada por falha.

${ }^{3}$ MTTR é a abreviatura de mean time torepair e é usado no contexto de manutenção para designar o período médio de tempo que uma manutenção dura até que o equipamento quebrado seja restabelecido à condição de funcionamento.
}

REMIPE- Revista de Micro e Pequenas Empresas e Empreendedorismo da Fatec Osasco 
Analisando os tempos de MTBF e MTTR obtidos fica evidente que a máquina que para com mais frequência devida a falhas é a onduladeira, o que é justificável pela forma como ela é estruturada através de múltiplos cabeçotes. Ocorre, porém, que o tempo em que a mesma se mantém parada devido a uma falha, é, em média, apenas 12 minutos, o que corresponde ao tempo de substituição do cabeçote danificado, portanto um tempo muito reduzido, o que diminui efetivamente o impacto dessas paradas no âmbito geral da fábrica.

Continuando com a análise, notamos que o Coladeira Modeti é a máquina que demora mais tempo para ser restaurada após uma falha, e ao mesmo tempo é uma das que param com mais frequência devido às falhas.

Um olhar crítico para esses tempos é fundamental para identificar perdas que podem ser evitadas. Para um entendimento mais concreto do prejuízo na forma de lucro cessante ${ }^{4}$ que cada parada para corretiva representa, contabilizamos o impacto econômico das mesmas como mostrado no gráfico 2 .

Gráfico 2: Lucro cessante por parada para corretiva:

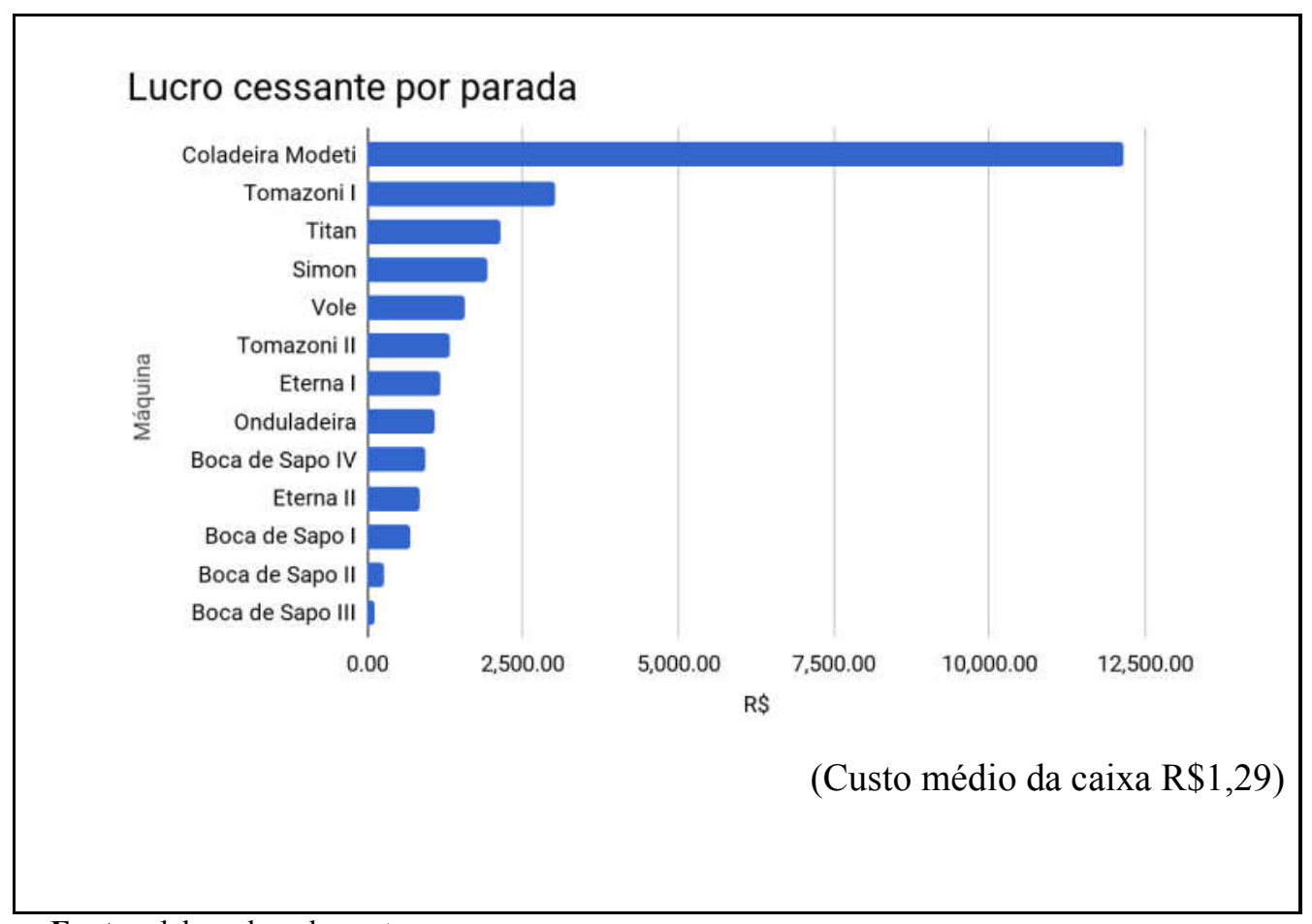

Fonte: elaborado pelos autores.

\footnotetext{
${ }^{4}$ Lucro cessante é o prejuízo oriundo da interrupção de quaisquer das atividades de uma empresa.
}

REMIPE- Revista de Micro e Pequenas Empresas e Empreendedorismo da Fatec Osasco 
Portanto, notamos que apesar de todos procedimentos realizados pela manutenção da empresa na onduladeira, ainda existem perdas por lucro cessante de até $\mathrm{R} \$ 12.000,00$ por parada, justificando assim uma manutenção mais estratégica na Coladeira Modeti.

Tabela 2 - Perdas e paradas:

\begin{tabular}{l|c|c|r|}
\hline \multicolumn{1}{c|}{ Máquina } & $\begin{array}{c}\text { Média mensal } \\
\text { de paradas }\end{array}$ & $\begin{array}{c}\text { Média mensal de } \\
\text { perdas } \\
\text { (caixas) }\end{array}$ & $\begin{array}{c}\text { Média mensal de } \\
\text { lucros cessantes } \\
\text { (R\$) }\end{array}$ \\
\hline Coladeira Modeti & 18 & 169400 & $2.622 .312,00$ \\
\hline Tomazoni I & 8 & 18683 & $289.218,00$ \\
\hline Titan & 10 & 16467 & $254.904,00$ \\
\hline Simon & 10 & 14932 & $206.400,00$ \\
\hline Vole & 11 & 13333 & $486.846,00$ \\
\hline Tomazoni II & 31 & 31450 & $42.570,00$ \\
\hline Eterna I & 3 & 2750 & $2.484 .540,00$ \\
\hline Onduladeira & 189 & 160500 & $32.920,80$ \\
\hline Boca de Sapo IV & 3 & 2127 & $41.765,60$ \\
\hline Eterna II & 11 & 7220 & $2.992,80$ \\
\hline Boca de Sapo I & 5 & 2610 & $1.496,40$ \\
\hline Boca de Sapo II & 1 & 193 & 97 \\
\hline Boca de Sapo III & 1 & & \\
\hline
\end{tabular}

Fonte: Elaborada pelos autores.

Cabe dizer que, certamente, é possível continuar determinando o tipo de manutenção que cada máquina, por meio da classificação $\mathrm{ABC}$. Destaca-se, porém, que aspectos como perdas financeiras por paradas e o tempo médio de reparo são itens que precisam ser inseridos nestes estudos pelas organizações, entre outros.

Continuando com uma análise crítica sobre o contexto de paradas, verifica-se que algumas máquinas podem ser substituídas mais facilmente de forma sistemática, enquanto estão em processo de manutenção. Tal fato permite uma continuidade de sua produção, ação que não é possível realizar com a máquina coladeira, por ser a única atualmente destinada exclusivamente para dobrar e colar caixas.

Conforme essa organização dos subgrupos, a coladeira Modeti não possui um método de substituição ou remanejamento em caso de paradas, o que acarreta em tentativas de cola manual pelos operadores durante as paradas.

REMIPE- Revista de Micro e Pequenas Empresas e Empreendedorismo da Fatec Osasco 
Figura 3: Coladeira Modeti parada:

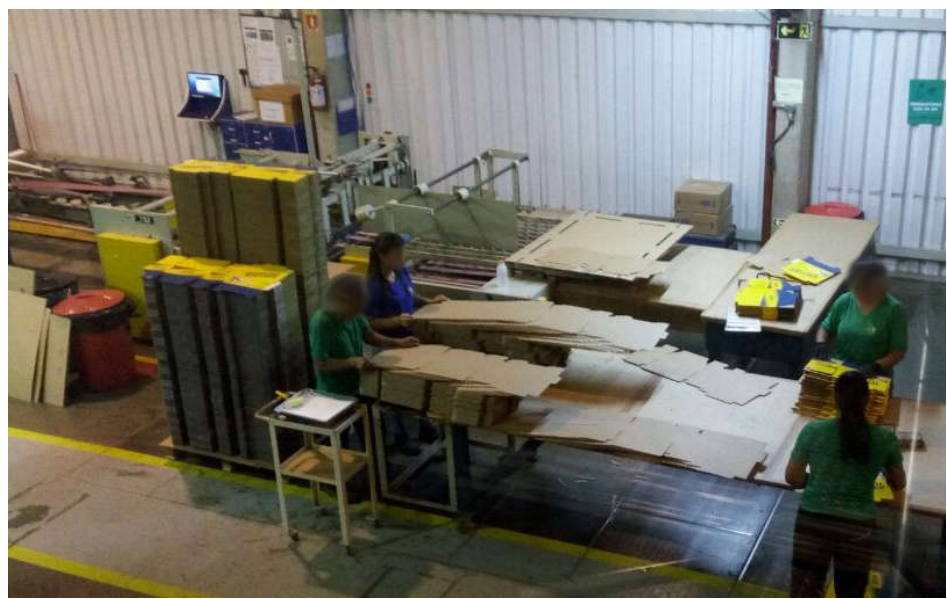

Fonte:Acervo dos autores.

Para entender melhor as paradas da máquina coladeira Modeti, foi separado o seu funcionamento em sistemas e subsistemas com seus respectivos componentes.

Figura 4: Sistemas da coladeira Modeti:

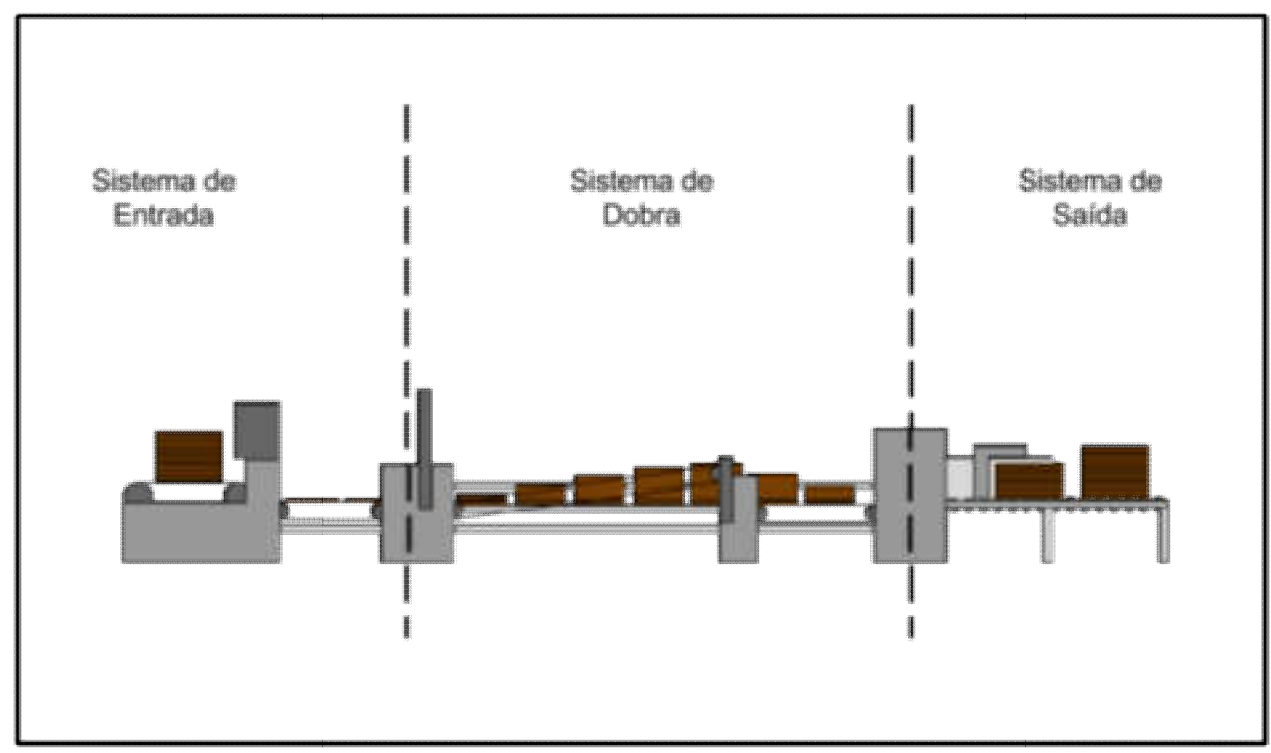

Fonte:Elaborado pelos autores.

Para estudo das falhas, foram coletadas informações acerca das ocorrências das mesmas em cada um dos sistemas da máquina, tomando por base ordens de serviços recebidos pela manutenção, durante o período analisado.

REMIPE- Revista de Micro e Pequenas Empresas e Empreendedorismo da Fatec Osasco V. 4, N¹, jan.-jun. 2018. 
Gráfico 3: Ocorrência de falhas nos sistemas:

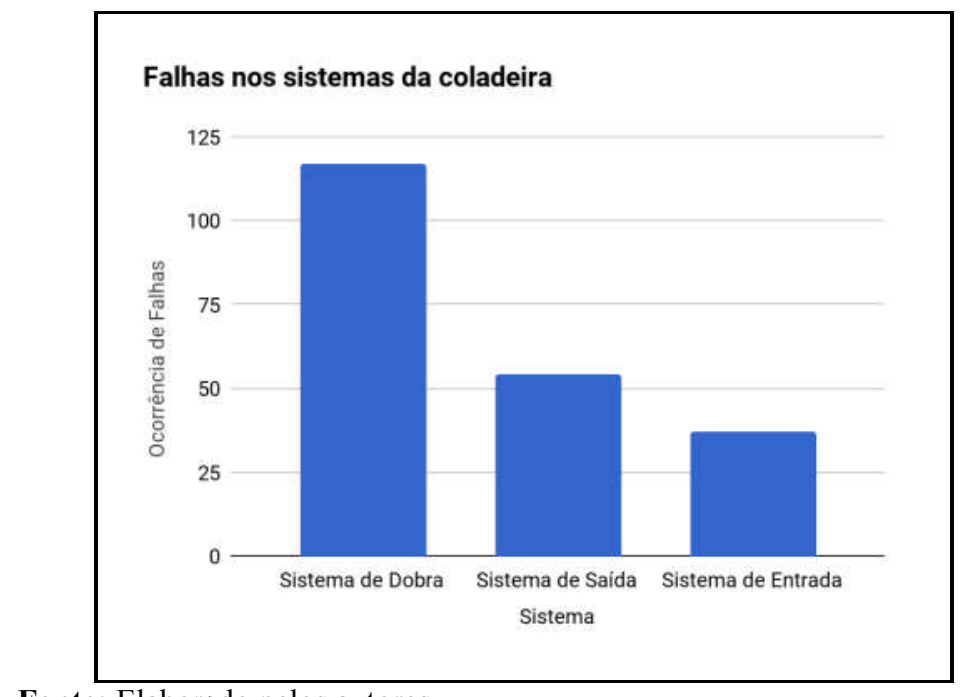

Fonte: Elaborado pelos autores.

Para um estudo mais abrangente da quebra no sistema de dobra, foi estabelecida a elaboração de um diagrama de Ishikawa e, para tanto, foi feito previamente um "brainstorm", conforme o procedimento de elaboração. Este procedimento sugeriu para um amplo entendimento de causas possíveis, entre as quais foram apresentadas sob situações hipotéticas: falta de lubrificação, falta de inspeção, falta de limpeza e desalinhamento. Dessas causas possíveis, foram deliberadas apenas duas uma vez que a falta de lubrificação e limpeza estão associadas a falta de inspeção do conjunto.

Finalmente, após a construção do entendimento preliminar sobre as causas possíveis, foram classificadas de acordo com os 6Ms do Diagrama de Ishikawa.

REMIPE- Revista de Micro e Pequenas Empresas e Empreendedorismo da Fatec Osasco 
Figura 5: Diagrama de Ishikawa da quebra do sistema de dobra:

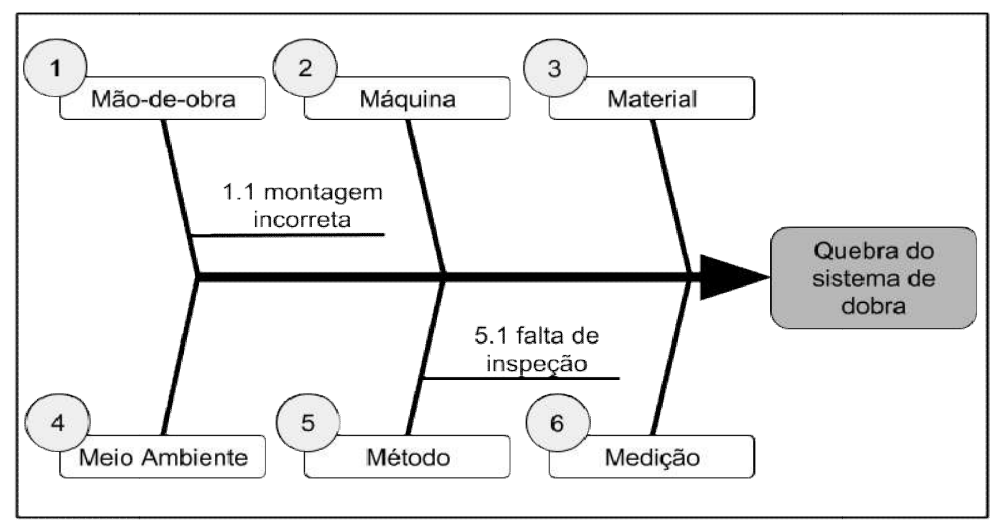

Fonte: elaborada pelos autores.

Para a solução desses problemas, a proposta é uma manutenção preventiva com um enfoque em cada detalhe do equipamento. $\mathrm{O}$ custo da mão de obra dos profissionais para a realização das manutenções preventivas por hora é calculado com base no salário mensal para um manutentor na empresa, que é de $\mathrm{R} \$ 4.200,00$ somado a $80 \%$ de encargos trabalhistas ( $\mathrm{R} \$ 3.360,00)$, dividido pela carga horária mensal de 220 horas resultando em $\mathrm{R} \$ 34,37$ por hora.

A figura 6 mostra uma parte do plano das atividades de manutenção, bem como o custos que precisam ser considerados para a realização, que atenda às demandas da máquina, no que se refere à cuidados de manutenção. 
Figura 6: Plano de manutenção preventiva:

\begin{tabular}{|c|c|c|c|c|c|c|c|c|}
\hline \multirow[b]{2}{*}{ Causa } & \multirow[b]{2}{*}{ Sistemas } & \multirow[b]{2}{*}{$\begin{array}{l}\text { Falhas } \\
\text { relacionadas }\end{array}$} & \multirow[b]{2}{*}{$\begin{array}{l}\text { Atividade de } \\
\text { manutenção }\end{array}$} & \multirow[b]{2}{*}{ Periodicidade } & \multicolumn{4}{|c|}{ Custos } \\
\hline & & & & & $\begin{array}{l}\text { Homem } \\
\mathrm{x} \text { hora }\end{array}$ & $\begin{array}{l}\text { Mão de } \\
\text { obra } \\
(\mathrm{R} \$)\end{array}$ & $\begin{array}{l}\text { Material } \\
(\mathrm{R} \$)\end{array}$ & $\begin{array}{l}\text { Total } \\
\text { anual } \\
(\mathrm{R} \$)\end{array}$ \\
\hline 5.1 & Dobra & $\begin{array}{l}\text { Travamento } \\
\text { das caixas }\end{array}$ & Alinhamento das guias & 15 dias & $1 \times 3$ & 103,11 & 0,00 & 2135,16 \\
\hline 1.1 & Entrada & $\begin{array}{c}\text { Quebra } \\
\text { das correias, } \\
\text { desalinhamento }\end{array}$ & $\begin{array}{c}\text { Balanceamento e } \\
\text { alinhamento das mesas }\end{array}$ & 1 mês & $1 \times 8$ & 274,96 & 0,00 & 2868,06 \\
\hline 5.1 & Entrada & $\begin{array}{l}\text { Travamento do } \\
\text { conjunto }\end{array}$ & $\begin{array}{c}\text { Limpar e lubrificar } \\
\text { coleiro }\end{array}$ & 1 mês & $1 \times 0,5$ & 17,19 & 1,00 & 191,22 \\
\hline 5.1 & Geral & $\begin{array}{l}\text { Quebra de } \\
\text { rolamento, desgaste } \\
\text { prematuro }\end{array}$ & Lubrificar mancais & 1 mês & $1 \times 1$ & 34,37 & 8,00 & 454,32 \\
\hline - & Entrada & $\begin{array}{c}\text { falta de cola e } \\
\text { desalinhamento da } \\
\text { engrenagem }\end{array}$ & $\begin{array}{c}\text { Verificar folgas nas } \\
\text { engrenagens do coleiro }\end{array}$ & 1 mês & $1 \times 1$ & 34,37 & 0,00 & 358,32 \\
\hline & & & & & & & & \\
\hline
\end{tabular}

Fonte: elaborada pelos autores.

Para a correta execução das atividades de manutenção, um dia a cada mês é dedicado para tal, portanto cronogramas de paradas planejadas são estabelecidos para manter uma previsão aos setores afetados pela parada da máquina, como o de produção.

As atividades devem ser devidamente planejadas por meio de cronogramas diários de execução da manutenção com a finalidade de organizar as atividades que serão desempenhadas pela equipe.

REMIPE- Revista de Micro e Pequenas Empresas e Empreendedorismo da Fatec Osasco 
Figura 7: Plano de execução da primeira preventiva:

\begin{tabular}{|c|c|c|c|c|c|c|c|c|c|c|c|c|c|c|c|c|c|}
\hline \multirow{2}{*}{\multicolumn{2}{|c|}{ Equipamento }} & \multicolumn{2}{|c|}{ Programado } & \multicolumn{4}{|c|}{ Custos } & & & & & & & & & & \\
\hline & & Data & Horário & Māo de obra & Materiais & \multirow{2}{*}{\multicolumn{2}{|c|}{\begin{tabular}{c|} 
Total \\
$\mathrm{R} \$ 2.610,10$
\end{tabular}}} & & & & & & & & & & \\
\hline \multicolumn{2}{|c|}{ Coladeira Modeti } & $25 / 01 / 2018$ & $7: 15$ as $17: 00$ & $\mathrm{R} \$ 1.031,10$ & $\mathrm{R} \$ 1.579,00$ & & & & & & & & & & & & \\
\hline \multirow{2}{*}{ Item } & \multirow{2}{*}{ Sistema/Conjunto } & \multirow{2}{*}{\multicolumn{2}{|c|}{ Serviço de Manutençāo }} & \multirow{2}{*}{ Responsavel } & \multirow{2}{*}{$\mathrm{H} \times \mathrm{h}$} & \multirow{2}{*}{ Status } & \multicolumn{11}{|c|}{ Duraçāo das atividades } \\
\hline & & & & & & & 7 & 8 & 9 & 10 & 11 & 12 & 13 & 14 & $4 \quad 15$ & 16 & 17 \\
\hline 1 & Dobra & \multicolumn{2}{|c|}{ Alinhamento das guias } & Bruno & $1 \times 3$ & & & & & & & & & & & & \\
\hline 2 & Entrada & \multicolumn{2}{|c|}{$\begin{array}{l}\text { Balanceamento e alinhamento das } \\
\text { mesas }\end{array}$} & Josvaldo & $1 \times 8$ & & & & & & & & & & & & \\
\hline 3 & Entrada & \multicolumn{2}{|c|}{ Limpar e lubrificar coleiro } & Albert & $1 \times 0,5$ & & & & & & & & & & & & \\
\hline 4 & Geral & \multicolumn{2}{|c|}{ Lubrificar mancais } & Albert & $1 \times 1$ & & & & & & & & & & & & \\
\hline 5 & Saida/Esquadro & \multicolumn{2}{|c|}{ Trocar o revestimento do rolo de saída } & Bruno, Albert & $2 \times 1$ & & & & & & & & & & & & \\
\hline 6 & Geral & \multicolumn{2}{|c|}{ Trocar polia do motor } & Bruno, Albert & $2 \times 1$ & & & & & & & & & & & & \\
\hline 7 & Geral & \multicolumn{2}{|c|}{$\begin{array}{l}\text { Verificar folgas nas engrenagens de } \\
\text { comando e subcomando }\end{array}$} & Bruno & $1 \times 1$ & & & & & & & & & & & & \\
\hline 8 & Dobra & \multicolumn{2}{|c|}{ Troca das correias da guia central } & Albert & $1 \times 4$ & & & & & & & & & & & & \\
\hline 9 & Dobra/Comando & \multicolumn{2}{|c|}{ Trocar correias auxiliares } & Bruno & $1 \times 1$ & & & & & & & & & & & & \\
\hline 10 & Dobra/Movimento & \multicolumn{2}{|c|}{ Verificar Motoredutores } & Bruno & $1 \times 0,5$ & & & & & & & & & & & & \\
\hline 11 & Entrada e saida & \multicolumn{2}{|c|}{ Trocar válvula pneumática } & Bruno & $1 \times 0,5$ & & & & & & & & & & & & \\
\hline 12 & Dobra/Comando & \multicolumn{2}{|c|}{ Verificar e esticar correias trapezoidais } & Bruno & $1 \times 0,17$ & & & & & & & & & & & & \\
\hline 13 & Dobra/Movimento & \multicolumn{2}{|c|}{ Verificar régua de guia das caixas } & Bruno & $1 \times 0,17$ & & & & & & & & & & & & \\
\hline 14 & Dobra/Comando & \multicolumn{2}{|c|}{ Trocar corrente de comando } & Bruno & $1 \times 1$ & & & & & & & & & & & & \\
\hline 15 & Geral & \multicolumn{2}{|c|}{$\begin{array}{l}\text { Verificar aperto e limpar painel de } \\
\text { comando }\end{array}$} & Albert & $1 \times 0,5$ & & & & & & & & & & & & \\
\hline 16 & Dobra/Movimento & \multicolumn{2}{|c|}{ Trocar régua de dobra } & Bruno, Josvaldo & $2 \times 2$ & & & & & & & & & & & & \\
\hline 17 & Dobra/Movimento & \multicolumn{2}{|c|}{ Verificar inversor de frequência } & Albert & $1 \times 0,5$ & & & & & & & & & & & & \\
\hline 18 & Dobra/Coleiro & Trocar rola & entos do motor & Albert & $1 \times 1$ & & & & & & & & & & & & \\
\hline
\end{tabular}

Fonte: elaborada pelos autores

\section{RESULTADOS}

Para analisar a viabilidade da implementação, verificamos os custos na tabela 4 .

Tabela 4: Custos anuais da preventiva:

\begin{tabular}{|l|l|}
\hline \multicolumn{1}{|c|}{ Recursos } & Custo anual (R\$) \\
\hline Materiais para troca & $18.533,53$ \\
\hline Mão de obra & $11.097,13$ \\
\hline Serviços de medição especializada & 880,00 \\
\hline Total & $30.510,66$ \\
\hline
\end{tabular}

Fonte: elaborada pelos autores.

Ao contabilizar o lucro cessante causado pela parada da máquina para manutenção preventiva, apura-se cerca de $\mathrm{R} \$ 560.000,00$. Portanto, tomando por base o tempo de paradas da máquina, registrados durante o primeiro semestre do ano, há uma média de 60,5 horas

REMIPE- Revista de Micro e Pequenas Empresas e Empreendedorismo da Fatec Osasco 
mensais e um custo unitário de $\mathrm{R} \$ 1,29$ por caixa. Ao realizar um investimento anual de $\mathrm{R} \$ 590.500,00$ resultará em um retorno de $\mathrm{R} \$ 2.266 .600,00$ elevando o faturamento da coladeira de $\mathrm{R} \$ 12.600 .000,00$, para $\mathrm{R} \$ 14.866 .600,00$ ao ano.

\section{CONSIDERAÇÕES FINAIS:}

Com o estudo de paradas e falhas no maquinário da empresa, foi possível identificar problemas relacionados com o funcionamento da coladeira, a qual não recebia o devido tratamento dentro da estrutura de manutenção estabelecida na planta da fábrica e evidenciouse a importância da manutenção de estratégia para o negócio.

Os métodos de manutenção preventiva foram de grande importância, pois, após o estabelecimento dos possíveis problemas, permitiram a prevenção de paradas não planejadas que geram grandes perdas para a produção. Esse tipo de manutenção, apesar de bastante cara, pode ser corretamente planejada e gerar bons resultados para o faturamento da empresa quando analisadas em relação às perdas em forma de lucro cessante.

De maneira geral, no ambiente industrial contemporâneo em que estamos, é esperada capacidade técnica para aplicar conceitos modernos de manutenção industrial mostrando eficiência na prestação de serviços em diversas situações e a quebra do paradigma de que a manutenção é um mal necessário. Aumentar a satisfação das partes interessadas é um objetivo comum de empresas certificadas e certamente o departamento de manutenção pode contribuir fortemente na busca por este objetivo.

\section{REFERÊNCIAS:}

Bracelpa, A Indústria de Celulose e Papel no Brasil.Disponível :

$<$ http://www.poyry.com.br/sites/www.poyry.com.br/files/media/related_material/16out27aabtcp.pdf> Acesso em 29/08/2017

ABNT, Associação Brasileira de Normas Técnicas, NBR 5462: Confiabilidade e mantenabilidade, Rio de Janeiro, 1941.

VIANA, H.R.G. PCM, Planejamento e controle da manutenção, Qualitymark, Rio de Janeiro, 2002.

KUME, H. Métodos estatísticos para melhoria da qualidade. 11. ed. São Paulo: Editora Gente, 1993.

REMIPE- Revista de Micro e Pequenas Empresas e Empreendedorismo da Fatec Osasco V. 4, N¹, jan.-jun. 2018. 
RAMOS, A.W. CEP para processos contínuos e em bateladas. São Paulo: Fundação Vanzolini, 2000.

WERKEMA, M.C.C. As ferramentas da qualidade no gerenciamento de processos. 2. ed. Belo Horizonte: UFMG; Fundação Christiano Ottoni, 1995.

MAURÍCIO, J.B. Manutenção Mecânica. Florianópolis : SENAI/SC, 2010. 